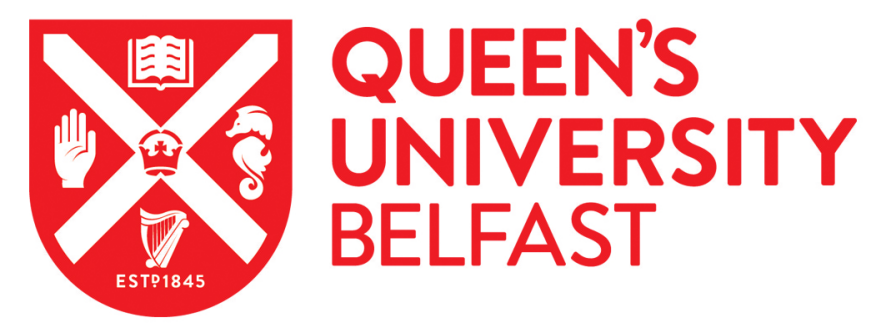

\title{
European Society of Endodontology position statement: Management of deep caries and the exposed pulp: Management of deep caries and the exposed pulp
}

European Society of Endodontology (ESE) developed by: (2019). European Society of Endodontology position statement: Management of deep caries and the exposed pulp: Management of deep caries and the exposed pulp. International Endodontic Journal, 52(7), 923-934. https://doi.org/10.1111/iej.13080

Published in:

International Endodontic Journal

Document Version:

Peer reviewed version

Queen's University Belfast - Research Portal:

Link to publication record in Queen's University Belfast Research Portal

Publisher rights

(C) 2019 International Endodontic Journal. Published by John Wiley \& Sons Ltd. This work is made available online in accordance with the publisher's policies. Please refer to any applicable terms of use of the publisher.

\section{General rights}

Copyright for the publications made accessible via the Queen's University Belfast Research Portal is retained by the author(s) and / or other copyright owners and it is a condition of accessing these publications that users recognise and abide by the legal requirements associated with these rights.

\section{Take down policy}

The Research Portal is Queen's institutional repository that provides access to Queen's research output. Every effort has been made to ensure that content in the Research Portal does not infringe any person's rights, or applicable UK laws. If you discover content in the Research Portal that you believe breaches copyright or violates any law, please contact openaccess@qub.ac.uk. 


\section{ARTICLE TYPE: ORIGINAL SCIENTIFIC ARTICLE}

\section{EUROPEAN SOCIETY OF ENDODONTOLOGY POSITION STATEMENT: MANAGEMENT OF DEEP CARIES AND THE EXPOSED PULP}

European Society of Endodontology (ESE) position statement developed by: Duncan $\mathrm{HF}^{1}$, Galler $\mathrm{KM}^{2}$, Tomson $\mathrm{PL}^{3}$, Simon $\mathrm{S}^{4}$, El-Karim $\mathrm{I}^{5}$, Kundzina $\mathrm{R}^{6}$, Krastl $\mathrm{G}^{7}$, Dammaschke $\mathrm{T}^{8}$, Fransson $\mathrm{H}^{9}$, Markvart $\mathrm{M}^{10}$, Zehnder $\mathrm{M}^{11}$, Bjørndal $\mathrm{L}^{10}$

Further additions, comments and consensus by ESE Executive Board members: Dummer PMH, Franco V, Gambarini G, Ørstavik D, Tjäderhane L, Whitworth J

Affiliations: ${ }^{1}$ Division of Restorative Dentistry, Dublin Dental University Hospital, Trinity College Dublin, Dublin, Ireland

${ }^{2}$ Department of Conservative Dentistry and Periodontology, University Hospital Regensburg, Regensburg, Germany

${ }^{3}$ Institute of Clinical Sciences, School of Dentistry, University of Birmingham, Birmingham, UK

${ }^{4}$ Paris Diderot University, Paris 7, Paris, France

${ }^{5}$ School of Medicine Dentistry and Biomedical Sciences, Queen's University Belfast, Belfast, UK

${ }^{6}$ Faculty of Health Sciences, Institute of Clinical Odontology, UiT the Arctic University of Norway, Troms $\varnothing$, Norway

${ }^{7}$ Department of Conservative Dentistry and Periodontology, University Hospital of Würzburg, Würzburg, Germany

${ }^{8}$ Department of Periodontology and Operative Dentistry, Westphalian Wilhelms-University, Münster, Germany

${ }^{9}$ Department of Endodontics, Faculty of Odontology, Malmö University, Malmö, Sweden

${ }^{10}$ Cariology and Endodontics, Department of Odontology, Faculty of Health and Medical

Sciences, University of Copenhagen, Copenhagen, Denmark

${ }^{11}$ Department of Preventive Dentistry, Periodontology and Cariology, University of Zurich, Zurich, Switzerland

Key words: dental pulp, caries, vital pulp treatment, pulp capping, pulpotomy, pulpitis, stepwise excavation, tertiary dentinogenesis

Correspondence: Dummer PMH, CEO of the European Society of Endodontology, Postboks 1237 Vika, 0110 Oslo, Norway. (e-mail: ceo@e-s-e.eu).

This article has been accepted for publication and undergone full peer review but has not been through the copyediting, typesetting, pagination and proofreading process, which may lead to differences between this version and the Version of Record. Please cite this article as doi: 10.1111/iej.13080

This article is protected by copyright. All rights reserved. 


\section{ESE-APPROVED DEFINITIONS AND TERMINOLOGY/GLOSSARY}

Deep caries: Caries reaching the inner quarter of dentine, but with a zone of hard or firm dentine between the caries and the pulp, which is radiographically detectable when located on an interproximal or occlusal surface. There is a risk of pulp exposure during operative treatment.

Extremely deep caries: Caries penetrating the entire thickness of the dentine, radiographically detectable when located on an interproximal or occlusal surface. Pulp exposure is unavoidable during operative treatment.

Soft, firm and hard dentine: Soft dentine can be excavated with minimum resistance using hand instruments, while firm dentine should be resistant to excavation using hand instruments. Hard dentine should be sound and resistant to probe penetration and scratching.

\section{Selective carious-tissue removal:}

Selective removal to soft dentine: Soft dentine is left only on the pulpal aspect of the cavity, while peripheral carious dentine is removed to hard dentine.

Selective removal to firm dentine: Firm dentine is left only on the pulpal aspect of the cavity, while peripheral carious dentine is removed to hard dentine.

Non-selective carious-tissue removal: Complete removal of soft and firm carious dentine from the periphery and central aspects of the cavity until hard dentine is reached.

Vital pulp treatment (VPT): Strategies aimed at maintaining the health of all or part of the pulp.

Indirect pulp capping: Application of a biomaterial onto a thin dentine barrier in a one-stage carious-tissue removal technique generally to hard dentine. Considered more aggressive than selective carious-tissue removal in one-stage and stepwise excavation. Leaves neither soft nor firm carious dentine behind.

Selective carious-tissue removal in one-stage: Application of a biomaterial onto a dentine barrier in an indirect one-stage selective carious-tissue removal technique. Removal to soft or firm dentine. Immediate placement of a permanent restoration.

Stepwise excavation: Application of a biomaterial in an indirect two-stage selective carious-tissue removal technique. Temporary restoration placement between visits and re-entry after 6-12 months. First stage involves selective carious removal to soft dentine, to an extent that facilitates proper placement of a temporary restoration, and second stage removal to firm dentine. Final placement of a permanent restoration.

Direct pulp capping: Following the preservation of an aseptic working field, application of a biomaterial directly onto the exposed pulp, prior to immediate placement of a permanent restoration.

This article is protected by copyright. All rights reserved. 
Class I: No preoperative presence of a deep carious lesion. Pulp exposure judged clinically to be through sound dentine with an expectation that the underlying pulp tissue is healthy (exposure due to a traumatic injury to the tooth or an iatrogenic exposure).

Class II: Preoperative presence of a deep or extremely deep carious lesion. Pulp exposure judged clinically to be through a zone of bacterial contamination with an expectation that the underlying pulp tissue is inflamed. Enhanced operative protocol recommended (aseptic procedure using magnification, disinfectant, and application of a hydraulic calcium silicate cement).

Partial pulpotomy: Removal of a small portion of coronal pulp tissue after exposure, followed by application of a biomaterial directly onto the remaining pulp tissue prior to placement of a permanent restoration.

Full pulpotomy: Complete removal of the coronal pulp and application of a biomaterial directly onto the pulp tissue at the level of the root canal orifice(s), prior to placement of a permanent restoration.

Pulpectomy: Total removal of the pulp from the root canal system followed by root canal treatment, prior to placement of a permanent restoration.

\section{ABSTRACT}

This position statement on the management of deep caries and the exposed pulp represents the consensus of an expert committee, convened by the European Society of Endodontology (ESE). Preserving the pulp in a healthy state with sustained vitality, preventing apical periodontitis and developing minimally invasive biologically based therapies are key themes within contemporary clinical endodontics. The aim of this statement is to summarise current best evidence on the diagnosis and classification of deep caries and caries-induced pulpal disease, as well as indicating appropriate clinical management strategies for avoiding and treating pulp exposure in permanent teeth with deep or extremely deep caries. In presenting these findings, areas of controversy, lowquality evidence and uncertainties are highlighted, prior to recommendations for each area of interest. A recently published review article provides more detailed information, and was the basis for this position statement (Bjørndal et al. 2019, International Endodontic Journal). The intention of this position statement is to provide the practitioner with relevant clinical guidance in this rapidly developing area. An update will be provided within 5 years as further evidence emerges.

This article is protected by copyright. All rights reserved. 


\section{SUMMARY OF KEY RECOMMENDATIONS}

\begin{tabular}{|c|c|}
\hline Position statement area & Recommendations \\
\hline Terminology & - ESE-approved definitions highlighted and listed. \\
\hline $\begin{array}{l}\text { Classifying disease } \\
\text { severity }\end{array}$ & $\begin{array}{l}\text { - Patient signs/symptoms and clinical findings, in combination with } \\
\text { caries depth assessed radiographically. } \\
\text { - Reversible and irreversible pulpitis remain useful, but require } \\
\text { revision to reflect the initial nature of irreversible damage, which is } \\
\text { partial and confined to the coronal pulp. }\end{array}$ \\
\hline $\begin{array}{l}\text { Diagnosing the pulpal } \\
\text { inflammatory state }\end{array}$ & $\begin{array}{l}\text { - History, clinical examination, pulp sensibility testing (electric and } \\
\text { cold), and diagnostically acceptable periapical radiographs required. } \\
\text { - CBCT use is not justified. } \\
\text { - Reversible pulpitis symptomless or has episodes of less intense, } \\
\text { shorter-lasting pain. } \\
\text { - Irreversible damage (partial or total) characterized by spontaneous, } \\
\text { radiating pain that lingers after removal of stimulus. }\end{array}$ \\
\hline Aseptic management & $\begin{array}{l}\text { - Tooth disinfection, sterile technique and rubber dam use at all times } \\
\text { throughout the management of deep caries whether pulp exposed } \\
\text { or not. }\end{array}$ \\
\hline $\begin{array}{l}\text { Managing deep caries to } \\
\text { avoid pulp exposure }\end{array}$ & $\begin{array}{l}\text { - What? Selective one-stage carious tissue removal or stepwise } \\
\text { excavation. } \\
\text { - When? Signs and symptoms of reversible pulpitis provided } \\
\text { radiographic assessment indicate caries to be no deeper than the } \\
\text { pulpal quarter. One surface (occlusal) carious lesions more } \\
\text { predictable than multi-surface lesions. }\end{array}$ \\
\hline $\begin{array}{l}\text { Managing carious pulp } \\
\text { exposure }\end{array}$ & $\begin{array}{l}\text { - What? Pulp capping (class I [traumatic/iatrogenic] or class II } \\
\text { [carious]), partial pulpotomy and full pulpotomy. } \\
\text { - When? Class II pulp cap or pulpotomy is indicated after the } \\
\text { exposure of asymptomatic or reversibly inflamed pulp tissue during } \\
\text { carious tissue excavation. } \\
\text { - For class II capping of deep carious lesions an enhanced protocol } \\
\text { should be used; including magnification, a disinfection irrigant and } \\
\text { the application of a hydraulic calcium silicate cement. } \\
\text { - Carious exposure with symptoms indicative of irreversible pulpitis, } \\
\text { when no rubber dam being used and instruments contaminated } \\
\text { during caries removal, should be treated aseptically with } \\
\text { pulpectomy. } \\
\text { - Alternatively full pulpotomy may be successful using an aseptic } \\
\text { technique in cases where there is partial irreversible pulpitis in the } \\
\text { coronal pulp, however, better long-term prospective randomised } \\
\text { data is required. }\end{array}$ \\
\hline
\end{tabular}

This article is protected by copyright. All rights reserved. 


\begin{tabular}{|c|c|}
\hline $\begin{array}{l}\text { Vital pulp treatment } \\
\text { materials }\end{array}$ & $\begin{array}{l}\text { - A hydraulic calcium silicate or a glass ionomer cement should be } \\
\text { placed over the deep dentine when pulp is not exposed. } \\
\text { - Hydraulic calcium silicate material placed directly onto the exposed } \\
\text { pulp in pulp capping, partial pulpotomy, or full pulpotomy prior to } \\
\text { definitive restoration. }\end{array}$ \\
\hline $\begin{array}{l}\text { Follow-up after vital pulp } \\
\text { treatment }\end{array}$ & $\begin{array}{l}\text { - Monitored by history and clinical radiographic examination at } 6 \\
\text { months, supplemented by periapical radiograph at one year. } \\
\text { - If symptoms persist or there is uncertainty regarding healing the } \\
\text { tooth should continue to be assessed at regular intervals. } \\
\text { - Thermal and electric pulp sensibility testing should be carried out to } \\
\text { monitor pulpal response, noting that teeth with full pulpotomy will } \\
\text { be unresponsive. }\end{array}$ \\
\hline
\end{tabular}

\section{INTRODUCTION}

The destructive nature of conventional dental treatment and concerns of overtreatment and the 'restorative cycle', have led the profession to promote minimally invasive biologically based treatment strategies. This has resulted in a shift in the management of deep caries from non-selective (complete) removal to selective (partial) removal, reducing the risk of pulp exposure (Innes et al. 2016). Contemporary management strategies for the cariously exposed pulp have seen the re-emergence and extension of vital pulp treatment (VPT) techniques such as partial and complete pulpotomy (Simon et al. 2013). As the maintenance of pulpal health including the prevention of apical periodontitis are core values in Endodontics, these developments are of fundamental importance to the profession. This position statement reflects the current views of the Society on these issues. It provides the practitioner with recommendations regarding the diagnosis and treatment of deep and extremely carious lesions and of the exposed pulp in permanent teeth based on current knowledge.

This statement limits itself to the management of extensive carious lesions, further subdivided into two radiographic categories, deep and extremely deep. This categorisation aims to quantify the risk of pulp exposure, as well as potentially highlight a threshold for the onset of more severe, likely to be irreversible, pulp inflammation (Reeves \& Stanley 1966). Deep carious lesions reach the inner quarter of dentine, but still with a zone of hard or firm dentine between the lesion and the pulp detectable radiographically, while an extremely deep carious lesion penetrates the entire thickness of the dentine clinically and radiographically (Bjørndal 2018, Bjørndal et al. 2018).

This article is protected by copyright. All rights reserved. 
Caries is a biofilm induced-disease, driven by a supply of fermentable carbohydrates (Nyvad et al. 2013, Pitts et al. 2017). The resulting ecological shift creates an acidogenic, cariogenic niche, which breaks down dental hard tissue to form a cavity (Dorozhkin \& Epple 2002, Schwendicke et al. 2016). Although pulpitis will accompany the carious process throughout its progression, it is not until the infected demineralized carious dentine is close to the pulp that the inflammatory response becomes severe and there is a risk of bacteria entering the pulp (Reeves \& Stanley 1966). In animal models employing healthy dentine, pulp tissue has an innate ability to repair if the bacterial challenge is removed and the tooth is suitably restored (Mjör \& Tronstad 1974, Warfvinge \& Bergenholtz 1986). Preservation of pulpal health maintains the pulp's developmental (primary and secondary dentinogenesis), defensive (tertiary dentinogenesis, immunoresponse) as well as retaining the pulp's mechanoreceptors.

Appropriate caries management within VPT aims to remove the microbial irritation and prevent new bacterial insult by placing a sealing dental biomaterial to protect exposed dentine and pulp from external stimuli. Therapeutically, VPT is quicker, less technically complex and invasive than pulpectomy and root canal treatment (RCT), while also reducing unwanted effects such as discolouration, fracture or residual periapical inflammation. Conversely, it can be argued that VPT and management of deep carious lesions is sensitive to ongoing bacterial contamination making the technique 'biologically demanding', often requiring magnification and expertise to treat. Thus, the overarching aims of caries management and VPT are to manage bacterial contamination, arrest caries progression, stimulate tertiary dentine formation, and promote pulpal repair as well as restoring the cavity to create a durable seal for long-term preservation of a symptom-free and functional tooth with a healthy pulp. The maintenance of an aseptic environment provides the optimal platform for successful VPT and necessitates the mandatory application of rubber dam and an aseptic procedure throughout the treatment even if the pulp is not exposed.

\section{CONSENSUS-BASED RECOMMENDATIONS}

\section{Classifications of disease severity to guide decision making in Vital Pulp Treatment}

Multi-centre prospective studies investigating the management of deep caries in adult patients have focused on the extent and depth of carious lesions (deep, extremely deep) radiographically as the principle inclusion criterion (Bjørndal et al. 2010, 2017). A detailed 
radiographic description of the caries was included in the experimental protocols; however, the pulpal symptomatology was interrogated in less detail (Bjørndal et al. 2010, 2017). A recent prospective study, investigating indirect pulp capping (IPC) in deep caries, included a pulpal classification as an inclusion criterion and noted the importance of pain severity on outcome (Hashem et al. 2015). On a similar theme, an editorial in the International Endodontic Journal described a new classification system for pulpitis linking symptoms rather than radiographic depth to management in VPT (Wolters et al. 2017), which highlights a lack of consensus in the classification of pulpitis. The American Association of Endodontists (AAE) endorsed the currently accepted classification of pulpal disease in 2013, describing pulpitis as either reversible or irreversible depending on clinical signs and symptoms (AAE 2013). The symptoms of reversible pulpitis range from no complaint to a sharp pain sensation with hot/cold stimuli and no tenderness to percussion; notably, the symptoms should resolve after removal of the stimulus. Spontaneous, radiating pain that lingers after removal of the stimulus and causes sleep disturbance tend to indicate irreversible pulpitis (Dummer et al. 1980). Clinical judgement is required, however, as irreversible pulpitis may be symptomless in anywhere between 14-60 \% of cases (Seltzer et al. 1963, Michaelson \& Holland 2002).

Although reversible and irreversible pulpitis may correlate with observational histological data (Ricucci et al. 2014), the decision to categorise a pulp as reversibly inflamed does not determine the actual potential of the inflamed tissue to repair. Therefore, it is critical that teeth undergoing less invasive carious tissue removal strategies, i.e. IPC, selective caries removal, stepwise excavation, pulp capping or pulpotomy after pulpal exposure are monitored postoperatively to ensure continuing pulpal health. At this moment it is accepted that the diagnoses irreversible and reversible pulpitis are clinically-based terms that are operational, but not biological. With the development of pulpotomy interventions, aimed at permanently maintaining part of the pulp in teeth with signs and symptoms of irreversible pulpitis (Taha \& Khazali 2017, Taha et al. 2017, Qudeimat et al. 2017), there have been calls to consider new more representative ways to classify pulpitis (Hashem et al. 2015, Wolters et al. 2017) with partial irreversible pulpitis perhaps a more accurate clinical reflection of the histological picture (Seltzer et al. 1963, Ricucci et al. 2014).

This article is protected by copyright. All rights reserved. 
Recommendation: Caries depth radiographically as well as clinical indicators of activity (e.g. symptoms, progression rate, colour, sensibility tests), should be used to assist clinical decision-making after history, meticulous examination of the mouth and relevant tooth, and special tests. The currently accepted diagnostic terms, reversible and irreversible pulpitis, remain useful but will require revision going forward. Vital pulps should be considered either reversibly inflamed or in the initial stages, show irreversible inflammation only in the area of the coronal pulp associated with the carious lesion. Without treatment this partial irreversible pulpitis will progress until the entire pulp is irreversibly inflamed and RCT is required.

\section{How should we diagnose the inflammatory state of the pulp?}

The outcome of VPT is dependent on the inflammatory state of the pulp and the presence of microorganisms, with carious exposures (class II) generally having a less favourable outcome compared with traumatic exposures (class I) (Al-Hiyasat et al. 2006); however, the current methods of accurately ascertaining the stage of pulpitis are poor (Mejàre et al. 2012). Assessment should begin with an accurate pain history including previous pain in the same tooth, detailing response to temperature extremes, spontaneity of pain, sleep disturbance and be supplemented with a meticulous clinical and periapical radiographic examination (indicating potential pulp necrosis and apical pathosis) to obtain a provisional primary diagnosis of the pulp status. Diagnostically acceptable periapical radiographs should use a paralleling technique, a film holder device and when assessing the image, the whole tooth should be visible as well as clear evidence of apical tissues $(>3 \mathrm{~mm}$ ) beyond the root tip with no interproximal overlap, distortion or processing errors (ESE 2006, Whaites \& Drage 2013). Although cone beam computed tomography (CBCT) has been proposed as an effective way to detect apical lesions associated with irreversible pulpitis (Abella et al. 2012) its use cannot be recommended for assessing pulpal inflammatory state. Thermal and electric pulp testing (EPT) remain the appropriate clinical tests to use, but are crude and non-quantitative (Villa-Chávez et al. 2013, Jespersen et al. 2014). Heat can be used to mimic the patient's symptoms and may remain useful in the diagnosis of pulpitis; but in general, the heat test has low accuracy (Mainkar \& Kim 2018). A painful response to cold stimuli remains the principle symptom of acute forms of pulpitis that makes patients seek emergency dental treatment (Rechenberg et al. 2016a). These diagnostic methods are 
subjective and relatively crude, only providing clinical guidance. Traditionally, these methods were not believed to reflect the true histopathological status of the pulp (Garfunkel et al. 1973, Dummer et al. 1980); however, this has recently been questioned (Ricucci et al. 2014).

All current techniques are limited both in their capacity to accurately describe the continuum of pulpal inflammation and to determine the link between inflammatory status and healing potential of the affected tissue. As a result, the development of new pulp tests and chairside assays of potential prognostic indicators (disease biomarkers) should be a focus for translational research (Swedish Council on Health Technology Assessment 2010, Rechenberg et al. 2016b, Ballal et al. 2017). In the absence of clinically available molecular tests of inflammation, the colour and intensity of pulp bleeding on exposure may provide a crude measure or surrogate marker of inflammation (Matsuo et al. 1996), and capacity to recover after treatment.

Recommendation: A detailed pain history and meticulous clinical examination supplemented with a high-quality periapical radiograph and pulp sensibility testing using low temperature cold testing in combination with EPT is necessary to assess the status of the pulp. The routine use of CBCT is not justified for assessing pulpitis. Vital pulps should be considered reversibly inflamed or alternatively partially or completely irreversibly inflamed under deep or extremely caries. Irreversible damage is characterized by episodes of spontaneous, radiating pain that lingers after removal of the stimulus. Reversible pulpitis is either symptomless or has episodes of less intense, shorter-lasting pain.

\section{How should we manage deep caries to avoid pulp exposure?}

One-stage selective carious-tissue removal to soft or firm dentine (Maltz et al. 2012) and two-stage stepwise excavation (Bjørndal et al. 2017) are indicated in deep carious lesions when the tooth is asymptomatic or has signs and symptoms indicative of reversible pulpitis. Non-selective (complete) caries removal is no longer regarded the treatment of choice in deep carious lesions, with recent consensus considering it to represent over-treatment (Schwendicke et al. 2016).

This article is protected by copyright. All rights reserved. 
These selective removal VPT approaches have demonstrated a 3-year success, defined as the absence of clinical symptoms and maintenance of pulp health, of $90 \%$ for one-stage selective removal and 70\% for stepwise excavation (Maltz et al. 2012); however, within this study many of the stepwise cases did not return for the second visit, making comparison difficult. Notably, one surface restorations performed better than two or moresurface restorations (Maltz et al. 2012), perhaps due to the practical difficulties for the operator attaining an effective marginal seal and the patient maintaining adequate oral hygiene interproximally. After 5 years, one-stage selective removal resulted in a survival rate of $80 \%$ (Maltz et al. 2017). Another 5-year randomised controlled trial reported the success rate of stepwise excavation after 5 years to be $60 \%$ compared with non-selective carious tissue removal of $46 \%$ (Bjørndal et al. 2017). Taken together, it can be concluded that the selective one-stage caries removal and stepwise excavation procedures have not been adequately compared in a randomized clinical trial.

Less invasive carious-tissue removal techniques are generally carried out using round burs and hand excavators (Maltz et al. 2012, Bjørndal et al. 2017). One and two stage selective carious-tissue removal techniques appear effective in reducing the risk of pulp exposure (Schwendicke et al. 2016), which is desirable, based on the assumption that pulp exposure is a negative prognostic factor in teeth with deep carious lesions (Bjørndal et al. 2010, 2017, Schwendicke et al. 2016). Advocates of single-visit caries removal suggest that re-entry is unnecessary (Maltz et al. 2012) while, supporters of stepwise techniques highlight that proper clinical evidence is still not available to show if there is a clinical difference between the approaches (Bjørndal 2018).

Regardless of the removal technique employed, carious tissue should be removed from the periphery of the cavity to hard dentine (i.e. non-selective removal), leaving soft or firm dentine only on the pulpal aspect of the cavity. This facilitates optimal bonding and sealing of the cavity from the oral environment. As dentine thickness over the pulp cannot be accurately assessed clinically, the use of a biologically based material is recommended, such as a hydraulic calcium silicate. Alternatively, a conventional glass ionomer cement, could be applied to the dentine barrier prior to restoration with a definitive resin-based composite restoration (Hashem et al. 2015, 2018). The maintenance of pulp health should be confirmed by pulp sensibility testing over time. Teeth exhibiting spontaneous or constant pain, a non-restorable crown, a heightened or lingering response to thermal pulp sensibility 
testing (indicating potential irreversible pulpitis) will have reduced prognosis and are not suitable candidates for procedures aimed at avoiding pulp exposure (Bjørndal et al. 2010, Swedish Council on Health Technology Assessment 2010). From a practical perspective, it is critical that the dentine is handled carefully and a suitable definitive restoration is placed to prevent further micro-leakage. Magnification should ideally be used throughout along with good contamination control using a rubber dam.

Recommendations: Selective carious tissue removal (one-stage or two-stage stepwise technique) is advocated in teeth with reversible pulpitis, provided radiographic assessment indicates caries has progressed no deeper than the pulpal quarter with a zone of dentine separating the carious lesion from the pulp chamber. One surface (occlusal) carious lesions are generally easier to manage and have more predictable outcomes. Asepsis should be preserved throughout the procedure including the use of rubber dam. A hydraulic calcium silicate or a glass ionomer cement should be placed over the deep dentine in both one and two-stage procedures. Current evidence does not indicate a preference for one material type over the other (Hashem et al. 2018). The material should be carefully placed to cover all remaining carious dentine and have sufficient thickness to withstand ingress of new bacteria into the lesion. The material should be able to promote, at least not inhibit, tertiary dentine formation.

\section{How should we manage carious pulp exposure?}

Treatment options after carious pulp exposure include direct pulp capping and pulpotomy (partial and full). In general, pulp preservation in cases of carious pulp exposure is only advocated in teeth with reversible pulpitis. Several recent studies have confirmed high levels of success after non-selective (complete) caries removal, leading to pulp exposure, and an enhanced VPT procedure involving the use of a hydraulic calcium silicate cement (not calcium hydroxide), an operating microscope (Bogen et al. 2009, Marques et al. 2015) and/or the use of a disinfection agent (Mente et al. 2014, Kundzina et al. 2017). Operator skill and experience may also be an important, if not independently tested, variable determining the success of VPT.

This article is protected by copyright. All rights reserved. 
This enhanced protocol may help to explain the difference between these studies and the relatively low success of a classic pulp capping protocol examined both retrospectively (Barthel et al. 2000) and prospectively in deep carious lesions (Bjørndal et al. 2010). Notably, high-quality clinical trials comparing these interventions are lacking and as a result, it remains to be elucidated if these recent promising results can be replicated in a primary care setting. Furthermore, for dentists competent in handling pulp tissues, nonselective carious removal and pulp exposure can offer an opportunity to assess pulp damage, the presence of necrosis in the pulp chamber, the level of pulp bleeding and the true extent of the carious destruction.

Pulpal health should be confirmed preoperatively by pulp sensibility testing and intraoperatively by the presence of vital tissue after exposure. Exclusion criteria may alter in the future; however, teeth exhibiting spontaneous or constant pain, an unrestorable crown, continuous uncontrollable pulp bleeding or the presence of necrotic tissue in the pulp chamber are generally not predictable candidates for pulp capping or partial pulpotomy (Bjørndal et al. 2010, Swedish Council on Health Technology Assessment 2010).

A direct pulp capping procedure should only be carried out after non-selective carious-tissue removal on a restorable tooth. Clinically, it is essential that during the VPT procedure, the tooth is isolated prior to pulpal exposure with rubber dam and disinfected. Magnification should be used throughout the procedure to ensure removal of all soft dentine and to inspect the pulp tissue. The damaged and exposed pulp tissue can be treated with the direct application of a capping material (pulp capping, class II), or removal of a small coronal part of the exposed pulp tissue (partial pulpotomy). Some degree of pulp tissue removal may be preferable in carious exposures to aid physical removal of the biofilm and superficial inflamed pulp tissue that may also contain microorganisms (Mejàre \& Cvek 1993, Barrieshi-Nusair \& Qudeimat 2006, Chailertvanitkul et al. 2014). If further caries excavation is necessary after exposure, a partial pulpotomy may be preferable due to the risk of transporting infected dentine chips into the pulp; however, the effect of such procedures may depend on operator skills and equipment (e.g. operating microscope).

The dentine should be carefully manipulated using sterile burs and sharp instruments, with a high-speed bur and water-coolant used for pulp tissue removal (Granath et al. 1971), prior to disinfection and control of pulpal bleeding. Haemostasis and disinfection should be achieved using cotton pellets soaked ideally with sodium 
hypochlorite (0.5-5\%) or chlorhexidine (0.2-2\%) (Mente et al. 2014, Kundzina et al. 2017, Harms et al. 2019). Although physiological saline has been the acceptable standard in class I pulp capping scenarios, it is limited by a lack of disinfection properties, while the use of ferric sulphate although an effective haemostatic agent, will distort the assessment of pulpal bleeding. If haemostasis cannot be controlled after 5 minutes, further pulp tissue should be removed (partial or full pulpotomy) and the wound surface rinsed as before. In cases with signs and symptoms indicative of irreversible pulpitis (i.e. partial irreversible pulpitis confined to the coronal pulp tissue), a full coronal pulpotomy can be carried out to the level of the root canal orifices with bleeding arrested as detailed previously. This procedure may be easier for practitioners without access to magnification to carry out than partial pulpotomy or even direct pulp capping. In all cases, a hydraulic calcium silicate cement should be placed directly onto the pulp tissue and the tooth definitively restored immediately to prevent further micro-leakage (Al-Hiyasat et al. 2006, Mente et al. 2010, Harms et al. 2019). If bleeding cannot be controlled after full pulpotomy, a pulpectomy and RCT should be carried out, provided the tooth is restorable.

Recommendations: Treatment of deep (and extremely deep) carious dentine should be done aseptically with sterile instruments, tooth disinfection and isolation by rubber dam. VPT in the form of a class II pulp cap or partial pulpotomy is indicated after exposure of reversibly inflamed pulp tissue during caries excavation. Carious exposure with symptoms indicative of irreversible pulpitis, no rubber dam and instruments contaminated during caries removal should be treated aseptically with pulpectomy. Alternatively, full pulpotomy may be successful in cases where there is partial irreversible pulpitis in the coronal pulp; however, better long-term prospective randomised data are required before this becomes the treatment of choice. For capping deep or extremely deep carious lesions an enhanced protocol is strongly recommended adding the use of magnification, a disinfection irrigant, and the use of a hydraulic calcium silicate cement.

\section{What materials should we use for VPT?}

Resin-based composites and dentine-bonding agents have been investigated in treatment of the exposed pulp, but are now contraindicated due to cytotoxicity (Krifka et al. 2012), absence of dentine formation over the wound site and poor clinical outcome (De Souza 
Costa et al. 2000). Hydraulic calcium silicate materials, such as mineral trioxide aggregate (MTA), have demonstrated superior histological (Aeinehchi et al. 2003, Nair et al. 2008) and clinical outcomes compared with calcium hydroxide in treatment of the exposed pulp (Cho et al. 2013, Hilton et al. 2013, Mente et al. 2014, Kundzina et al. 2017).

Furthermore, there is evidence to suggest that hydraulic calcium silicate cements can be used when the pulp is not exposed (e.g. IPC) after deep caries removal (Leye Benoist et al. 2012, Petrou et al. 2014, Hashem et al. 2015). Although longer-term clinical and radiographic follow up demonstrated no significant improvement compared with glass ionomer cements in terms of symptoms and pulp status (Hashem et al. 2018). A range of hydraulic calcium silicate cements are available, which share similar biological properties, but exhibit chemical differences, which influences radiopacity, setting time and the potential to discolour the tooth (Parirokh et al. 2018).

Recommendations: A hydraulic calcium silicate material or glass ionomer should be placed during procedures aimed at avoiding pulp exposure onto the residual dentine prior to a definitive restoration. After pulp exposure, during a pulp capping, partial pulpotomy, or full pulpotomy a hydraulic calcium silicate material should be placed directly onto the exposed pulp prior to definitive restoration.

\section{How should VPT cases be followed-up and what is the expected prognosis?}

VPT procedures should be assessed 6 and 12 months postoperatively and at yearly intervals (if necessary) for 4 years thereafter. The tooth should respond positively to pulp sensibility testing within normal limits. It should be noted that teeth may not respond (e.g. older patients, multi-surface resin based composite or ceramic restorations) and that teeth, which have undergone full pulpotomy are expected to be unresponsive to testing. The patient should be free of pain and other symptoms, there should be an absence of apical periodontitis and signs of internal root resorption, while in immature teeth, there should also be radiological evidence of continued root formation (ESE 2006). Success, defined as absence of symptoms and maintenance of pulp vitality after a least one year, is in the region of $70-90 \%$ for selective, one and two-stage carious removal procedures (Bjørndal et al. 2010, Maltz et al. 2012, Hashem et al. 2015, Bjørndal et al. 2017, Ali et al. 2018, Hashem et al. 2018). Equally, in mature permanent teeth with caries and symptoms no worse than 
reversible pulpitis, exposing the pulp and capping with a calcium silicate material, is also a predictable procedure (Mente et al. 2014, Marques et al. 2015, Kundzina et al. 2017). However, data on the carious penetration depth in these studies was not well defined (Marques et al. 2015, Kundzina et al. 2017), and some of the sample material in these studies comprised mechanical exposures (class I pulp caps) (Mente et al. 2014). All things considered, best current evidence would indicate that a modern pulp capping procedure (class II pulp caps) should be successful in approximately $80-90 \%$ of cases (Hilton et al. 2013, Marques et al. 2015, Kundzina et al. 2017).

Other factors may affect prognosis to a varying degree. Young patients are considered good candidates for VPT due to an enhanced pulpal blood supply, open root apices and pulps free of age-related change (Goodis et al. 2012). VPT after pulp exposure, based on observational data, retrospective data (Mente et al. 2010, Kunert et al. 2015, Linsuwanont et al. 2017, Harms et al. 2019) and randomised clinical trials (Asgary et al. 2015, Kang et al. 2017), however, indicates a similar distribution of successes and failures irrespective of the patients age albeit the data is heterogeneous and the quality of evidence sup-optimal. Within a randomised trial, it was demonstrated that patient age was a more important variable after pulp exposure than it was when the pulp was not exposed during treatment (Bjørndal et al. 2017). The size of the exposure site is also not a significant factor in success (Mejàre \& Cvek 1993, Dammaschke et al. 2010), although one study suggested that if the exposure were very large $(>5 \mathrm{~mm}$ ) it was less successful (Chailertvanitkul et al. 2014).

Recent evidence demonstrates success of full pulpotomy after one year to range between $75-95 \%$, even in teeth with signs and symptoms indicative of irreversible pulpitis (Asgary \& Eghbal 2013, Asgary et al. 2015, 2017, 2018, Galani et al. 2017, Linsuwanont et al. 2017, Qudeimat et al. 2017, Taha et al. 2017). Notably, these success rates are difficult to compare with other VPT techniques, as the maintenance of pulp health cannot be verified by pulp sensibility testing. The potential of full pulpotomy in teeth with signs and symptoms indicative of partial irreversible pulpitis is clear and although the evidence is preliminary, it indicates that an extension of the traditional rationale for VPT is likely in the future.

This article is protected by copyright. All rights reserved. 
Recommendations: After VPT teeth should be carefully monitored by history and clinical examination at 6 months, supplemented by periapical radiograph at one year. If symptoms persist or there is uncertainty regarding healing the tooth should continue to be assessed at regular intervals. Cold and electric pulp sensibility testing should be carried out to monitor pulpal response, noting that teeth with full pulpotomy will be unresponsive.

\section{Summary and concluding remarks}

Developments in understanding of the defensive response of the dentine-pulp complex and a drive to develop minimally invasive treatment solutions in Endodontics have created significant interest in vital pulp treatment. It must be highlighted that there is a paucity of high-quality comparative research on mature carious permanent teeth that addresses many of the central questions. Although this area is likely to modify in the future this ESE Position Statement must be cautious in recommending treatments of choice that are preliminary and not supported by robust long-term evidence.

\section{REFERENCES}

Abella F, Patel S, Duran-Sindreu F, Mercadé M, Bueno R, Roig M (2012) Evaluating the periapical status of teeth with irreversible pulpitis by using cone-beam computed tomography scanning and periapical radiographs. Journal of Endodontics 38, 1588-91.

Aeinehchi M, Eslami B, Ghanbariha M, Saffar AS (2003) Mineral trioxide aggregate (MTA) and calcium hydroxide as pulp-capping agents in human teeth: a preliminary report. International Endodontic Journal 36, 225-31.

Al-Hiyasat AS, Barrieshi-Nusair KM, Al-Omari MA (2006) The radiographic outcomes of direct pulp-capping procedures performed by dental students: a retrospective study. Journal of the American Dental Association 137, 1699-705.

American Association of Endodontists (2013) Endodontic diagnosis. https://www.aae.org accessed $3^{\text {rd }}$ September 2018.

Asgary S, Eghbal MJ (2013) Treatment outcomes of pulpotomy in permanent molars with irreversible pulpitis using biomaterials: A multi-center randomized controlled trial. Acta Odontologica Scandinavica 71, 130-6.

Asgary S, Eghbal MJ, Fazlyab M, Baghban AA, Ghoddusi J (2015) Five-year results of vital pulp therapy in permanent molars with irreversible pulpitis: A non-inferiority multicenter randomized clinical trial. Clinical Oral Investigations 19, 335-41.

This article is protected by copyright. All rights reserved. 
Asgary S, Eghbal MJ, Bagheban AA (2017) Long-term outcomes of pulpotomy in permanent teeth with irreversible pulpitis: A multi-center randomized controlled trial. American Journal of Dentistry 30, 151-5.

Asgary S, Hassanizadeh R, Torabzadeh H, Eghbal MJ (2018) Treatment outcomes of 4 vital pulp therapies in mature molars. Journal of Endodontics 44, 529-35.

Ballal V, Rao S, Bagheri A, Bhat V, Attin T, Zehnder M (2017) MMP-9 in dentinal fluid correlates with caries lesion depth. Caries Research 51, 460-5.

Barrieshi-Nusair KM, Qudeimat MA (2006) A prospective clinical study of mineral trioxide aggregate for partial pulpotomy in cariously exposed permanent teeth. Journal of Endodontics 32, 731-5.

Barthel CR, Rosenkranz B, Leuenberg A, Roulet RF (2000) Pulp capping of carious exposures: treatment outcome after 5 and 10 years: a retrospective study. Journal of Endodontics 26, 525-8.

Bjørndal L, Reit C, Bruun G, et al. (2010) Treatment of deep caries lesions in adults: randomized clinical trials comparing stepwise vs. direct complete excavation, and direct pulp capping vs. partial pulpotomy. European Journal of Oral Science 118, 290-7.

Bjørndal L, Fransson H, Bruun G, et al. (2017) Randomized clinical trials on deep carious lesions: 5-year follow-up. Journal of Dental Research 96, 747-53.

Bjørndal L (2018) Caries pathology and management in deep stages of lesion formation. In: Bjørndal L, Kirkevang L-L, Whitworth J, 3. edn. Textbook of Endodontology. Oxford; UK. Wiley Blackwell. pp. 61-78.

Bjørndal L, Simon S, Tomson PL, Duncan HF (2019) Management of deep caries and the exposed pulp. International Endodontic Journal [in press]

Bogen G, Kim JS, Bakland LK (2008) Direct pulp capping with mineral trioxide aggregate: an observational study. Journal of the American Dental Association 139, 305-15.

Chailertvanitkul P, Paphangkorakit J, Sooksantisakoonchai N, et al. (2014) Randomized control trial comparing calcium hydroxide and mineral trioxide aggregate for partial pulpotomies in cariously exposed pulps of permanent molars. International Endodontic Journal 47, 835-42.

Cho SY, Seo DG, Lee SJ, Lee J, Lee SJ, Jung IY (2013) Prognostic factors for clinical outcomes according to time after direct pulp capping. Journal of Endodontics 39, 327-31.

Dammaschke T, Leidinger J, Schäfer E (2010) Long-term evaluation of direct pulp capping-treatment outcomes over an average period of 6.1 years. Clinical Oral Investigations 14, 559-67.

This article is protected by copyright. All rights reserved. 
De Souza Costa CA, Hebling J, Hanks CT (2000) Current status of pulp capping with dentin adhesive systems: a review. Dental Materials 16, 187-97.

Dorozhkin SV, Epple M (2002) Biological and medical significance of calcium phosphates. Angewandte Chemie International Edition 41, 3130-46.

Dummer PM, Hicks R, Huws D (1980) Clinical signs and symptoms in pulp disease. International Endodontic Journal 13, 27-35.

European Society of Endodontology (2006) Quality guidelines for endodontic treatment: consensus report of the European Society of Endodontology. International Endodontic Journal 39, 921-30.

Galani M, Tewari S, Sangwan P, Mittal S, Kumar V, Duhan J (2017) Comparative evaluation of postoperative pain and success rate after pulpotomy and root canal treatment in cariously exposed mature permanent molars: A randomized controlled trial. Journal of Endodontics 43, 1953-62.

Garfunkel A, Sela J, Ulmansky (1973) Dental pulp pathosis: clinicopathologic correlations based on 109 cases. Oral Surgery, Oral Medicine, Oral Pathology 35, 110-7.

Goodis HE, Kahn A, Simon S (2012) Aging and the pulp. In: Hargreaves K, Goodis HE, Tay F, eds. Seltzer and Bender's Dental Pulp, 2nd edn; Berlin, Germany: Quintessenz.

Granath LE, Hagman G (1971) Experimental pulpotomy in human bicuspids with reference to cutting technique. Acta Odontologica Scandinavica 29, 155-63.

Harms CS, Schäfer E, Dammaschke T (2019) Clinical evaluation of direct pulp capping using a calcium silicate cement - treatment outcomes over an average period of 2.3 years. Clinical Oral Investigations [accepted] DOI: 10.1007/s00784-018-2767-5.

Hashem D, Mannocci F, Patel S, et al. (2015) Clinical and radiographic assessment of the efficacy of calcium silicate indirect pulp capping: a randomized controlled clinical trial. Journal of Dental Research 94, 562-8.

Hashem D, Mannocci F, Patel S, et al. (2018) Evaluation of the efficacy of calcium silicate vs. glass ionomer cement indirect pulp capping and restoration assessment criteria: a randomised controlled clinical trial-2-year results. Clinical Oral Investigations doi: 10.1007/s00784-018-2638-0. [Epub ahead of print].

Hilton TJ, Ferracane JL, Mancl L, Northwest Practice-based Research Collaborative in Evidence-based Dentistry (NWP) (2013) Comparison of $\mathrm{CaOH}$ with MTA for direct pulp capping: a PBRN randomized clinical trial. Journal of Dental Research 92, 16-22S.

Innes NP, Frencken JE, Bjørndal L, et al. (2016) Managing carious lesions: consensus recommendations on terminology. Advances in Dental Research 28, 49-57.

This article is protected by copyright. All rights reserved. 
Jespersen JJ, Hellstein J, Williamson A, Johnson WT, Qian F (2014) Evaluation of dental pulp sensibility tests in a clinical setting. Journal of Endodontics 40, 351-4.

Kang CM, Sun Y, Song JS, et al. (2017) A randomized controlled trial of various MTA materials for partial pulpotomy in permanent teeth. Journal of Dentistry 60, 8-13.

Krifka S, Seidenader C, Hiller KA, Schmalz G, Schweikl H (2012) Oxidative stress and cytotoxicity generated by dental composites in human pulp cells. Clinical Oral Investigations $16,215-24$.

Kundzina R, Stangvaltaite L, Eriksen HM, Kerosuo E (2017) Capping carious exposures in adults: a randomized controlled trial investigating mineral trioxide aggregate versus calcium hydroxide. International Endodontic Journal 50, 924-32.

Kunert GG, Kunert IR, da Costa Filho LC, de Figueiredo JAP (2015) Permanent teeth pulpotomy survival analysis: Retrospective follow-up. Journal of Dentistry 43, 1125-31.

Leye Benoist F, Gaye Ndiaye F, Kane AW, Benoist HM, Farge P (2012) Evaluation of mineral trioxide aggregate (MTA) versus calcium hydroxide cement (Dycal) in the formation of a dentine bridge, a randomised controlled trial. International Dental Journal 62, 33-9.

Linsuwanont P, Wimonsutthikul K, Pothimoke U, Santiwong B (2017) Treatment outcomes of mineral trioxide aggregate pulpotomy in vital permanent teeth with carious pulp exposure: The retrospective study. Journal of Endodontics 43, 225-30.

Mainkar A, Kim SG (2018) Diagnostic accuracy of 5 dental pulp tests: A systematic review and meta-analysis. Journal of Endodontics 44, 694-702.

Maltz M, Garcia R, Jardim JJ, et al. (2012) Randomized trial of partial vs. stepwise caries removal: 3-year follow-up. Journal of Dental Research 91, 1026-31.

Maltz M, Koppe B, Jardim JJ, et al. (2017) Partial caries removal in deep caries lesions: A 5year multicenter randomized controlled trial. Clinical Oral Investigations 22,1337-43.

Marques MS, Wesselink PR, Shemesh H (2015) Outcome of direct pulp capping with mineral trioxide aggregate. Journal of Endodontics 41, 1026-31.

Matsuo T, Nakanishi T, Shimizu H, Ebisu S (1996) A clinical study of direct pulp capping applied to carious-exposed pulps. Journal of Endodontics 22, 551-6.

Mejàre I, Cvek M (1993) Partial pulpotomy in young permanent teeth with deep carious lesions. Endodontics and Dental Traumatology 9, 238-42.

Mejàre IA, Axelsson S, Davidson T, Frisk F, Hakeberg M, Kvist T, et al (2012). Diagnosis of the condition of the dental pulp: a systematic review. International Endodontic Journal 45, 597613.

This article is protected by copyright. All rights reserved. 
Mente J, Geletneky B, Ohle M, et al. (2010) Mineral trioxide aggregate or calcium hydroxide direct pulp capping: An analysis of the clinical treatment outcome. Journal of Endodontics 36, 806-13.

Mente J, Hufnagel S, Leo M, et al. (2014) Treatment outcome of mineral trioxide aggregate or calcium hydroxide direct pulp capping: long-term results. Journal of Endodontics 40, 1746-51.

Michaelson PL, Holland GR (2002) Is pulpitis painful? International Endodontic Journal 35, 829-32.

Mjör IA, Tronstad L (1974) The healing of experimentally induced pulpitis. Oral Surgery, Oral Medicine, Oral Pathology 38, 115-21.

Nair PNR, Duncan HF, Pitt Ford TR, Luder HU (2008) Histological, ultrastructural and quantitative investigations on the response of healthy human pulps to experimental capping with mineral trioxide aggregate: a randomized controlled trial. International Endodontic Journal 41, 128-50.

Nyvad B, Crielaard W, Mira A, Takahashi N, Beighton D (2013) Dental caries from a molecular microbiological perspective. Caries Research 47, 89-102.

Parirokh M, Torabinejad M, Dummer PMH (2018) Mineral trioxide aggregate and other bioactive endodontic cements: an updated overview - part I: vital pulp therapy. International Endodontic Journal 51, 177-205.

Petrou MA, Alhamoui FA, Welk A, Altarabulsi MB, Alkilzy M, Splieth CH (2014) A randomized clinical trial on the use of medical Portland cement, MTA and calcium hydroxide in indirect pulp treatment. Clinical Oral Investigations 18, 1383-9.

Pitts NB, Zero DT, Marsh PD, et al. (2017) Dental caries. Nature Reviews Disease Primers 25, 17030. doi: 10.1038/nrdp.2017.30.

Qudeimat MA, Alyahya A, Hasan AA (2017) Mineral trioxide aggregate pulpotomy for permanent molars with clinical signs indicative of irreversible pulpitis: a preliminary study. International Endodontic Journal 50, 126-34.

Rechenberg DK, Held U, Burgstaller JM, Bosch G, Attin T (2016a) Pain levels and typical symptoms of acute endodontic infections: a prospective, observational study. BMC Oral Health 16, 61.

Rechenberg DK, Galicia JC, Peters OA (2016b) Biological markers for pulpal inflammation: A systematic review. PLoS One 11, e0167289.

Reeves R, Stanley HR (1966) The relationship of bacterial penetration and pulpal pathosis in carious teeth. Oral Surgery, Oral Medicine, Oral Pathology 22, 59-65. 
Ricucci D, Loghin S, Siqueira Jr J (2014) Correlation between clinical and histologic pulp diagnoses. Journal of Endodontics 40, 1932-9.

Schwendicke F, Frencken JE, Bjørndal L, et al. (2016) Managing carious lesions: consensus recommendations on carious tissue removal. Advances in Dental Research 28, 58-67.

Seltzer S, Bender IB, Ziontz M (1963) The dynamics of pulpal inflammation: correlations between diagnostic data and actual histologic findings in the pulp. Oral Surgery, Oral Medicine, Oral Pathology 16, 871-6.

Simon S, Perard M, Zanini M, et al. (2013) Should pulp chamber pulpotomy be seen as a permanent treatment? Some preliminary thoughts. International Endodontic Journal 46, 7987.

Swedish Council on Health Technology Assessment (2010) Methods of diagnosis and treatment in endodontics: a systematic review. Assessment No. 203. [WWW document] URL https://www.sbu.se/contentassets/eafcce68f3aa438cb932c76702cde403/methods-ofdiagnosis-and-treatment-in-endodontics_full.pdf.

Taha NA, Khazali MA (2017) Partial pulpotomy in mature permanent teeth with clinical signs indicative of irreversible pulpitis: A Randomized Clinical Trial. Journal of Endodontics 43, 1417-21.

Taha NA, Ahmad MB, Ghanim A (2017) Assessment of mineral trioxide aggregate pulpotomy in mature permanent teeth with carious exposures. International Endodontic Journal 50, 117-25.

Villa-Chávez CE, Patiño-Marín N, Loyola-Rodríguez JP, Zavala-Alonso NV, Martínez-Castañón GA, Medina-Solís CE (2013) Predictive values of thermal and electrical dental pulp tests: a clinical study. Journal of Endodontics 39, 965-9.

Warfvinge J, Bergenholtz G (1986) Healing capacity of human and monkey dental pulps following experimentally-induced pulpitis. Endodontics and Dental Traumatology 2, 256-62.

Whaites E, Drage N (2013) Periapical radiography. In: Whaites E, Drage N, ed. Essentials in Dental Radiography and Radiology, $3^{\text {rd }}$ edn; pp 85-119. London, UK. Churchill Livingstone.

Wesselink P (1990) Conventional root-canal therapy III: root filling. In: Harty FJ, ed. Endodontics in Clinical Practice, 3rd edn; pp. 186-223. London, UK: Butterworth.

Wolters WJ, Duncan HF, Tomson PL, et al. (2017) Minimally invasive endodontics: a new diagnostic system for assessing pulpitis and subsequent treatment needs. International Endodontic Journal 50, 825-9.

This article is protected by copyright. All rights reserved. 